\title{
Leptin Excites Proopiomelanocortin Neurons via Activation of TRPC Channels
}

\author{
Jian Qiu, ${ }^{1}$ Yuan Fang, ${ }^{1}$ Oline K. Rønnekleiv, ${ }^{1,2,3}$ and Martin J. Kelly ${ }^{1}$ \\ Departments of ${ }^{1}$ Physiology and Pharmacology and ${ }^{2}$ Anesthesiology and Perioperative Medicine and ${ }^{3}$ Division of Neuroscience, Oregon National Primate \\ Research Center, Oregon Health \& Science University, Portland, Oregon 97239-3089
}

Leptin can exert its potent appetite-suppressing effects via activation of hypothalamic proopiomelanocortin (POMC) neurons. It depolarizes POMC neurons via activation of a yet unidentified nonselective cation current. Therefore, we sought to identify the conductance activated by leptin using whole-cell recording in EGFP-POMC neurons from transgenic mice. The TRPC channel blockers SKF96365 (1-[ $\beta$-[3-(4-methoxyphenyl)propoxy]-4-methoxyphenethyl]-1H-imidazole hydrochloride), flufenamic acid, and 2-APB (2-aminoethyl diphenylborinate) potently inhibited the leptin-induced current. Also, lanthanum $\left(\mathrm{La}^{3+}\right)$ and intracellular $\mathrm{Ca}^{2+}$ potentiated the effects of leptin. Moreover, the diacylglycerol-permeable analog OAG (2-acetyl-1-oleoyl-sn-glycerol) failed to activate any TRPC current. Using $\mathrm{a} \mathrm{Cs}^{+}$-gluconate-based internal solution, the leptin-activated current reversed near $-20 \mathrm{mV}$. After replacement of external $\mathrm{Na}^{+}$and $\mathrm{K}^{+}$ with $\mathrm{Cs}^{+}$, the reversal shifted to near $0 \mathrm{mV}$, and the $I / V$ curve exhibited a negative slope conductance at voltages more negative than -40 mV. Based on scRT-PCR, TRPC1 and TRPC4 -7 mRNA were expressed in POMC neurons, with TRPC5 being the most prevalent. The leptin-induced current was blocked by the Jak2 inhibitor AG490, the PI3 kinase inhibitor wortmannin, and the phospholipase C inhibitors, U73122 and ET-18-OCH3. Notably, we identified PLC $\gamma 1$ transcripts in the majority of POMC neurons. Therefore, leptin through a Jak2-PI3 kinase-PLC $\gamma$ pathway activates TRPC channels, and TRPC1, 4, and 5 appear to be the key channels mediating the depolarizing effects of leptin in POMC neurons.

\section{Introduction}

Leptin is derived from adipocytes, and it binds to its long-form receptor (LRb), which is expressed in a number of hypothalamic nuclei, including the arcuate nucleus (Elmquist et al., 1998). Within the arcuate nucleus, LRb has been localized in proopiomelanocortin (POMC) and neuropeptide Y neurons. Genetic mutations in leptin or its receptor are associated with profound metabolic and physiological abnormalities such as obesity and infertility.

A rapid but vital action of leptin in acute suppression of food intake is to depolarize and augment firing in POMC neurons (Cowley et al., 2001; Hill et al., 2008). The leptin-induced depolarization of arcuate POMC and paraventricular nucleus neurons is thought to be via the activation of a nonselective cation channel (NSCC) because the depolarization is associated with a small inward current that reverses at approximately $-20 \mathrm{mV}$ (Powis et al., 1998; Cowley et al., 2001). However, no one has identified the NSCC channel that is activated by leptin. A potential candidate was a hyperpolarization-activated cation current $\left(I_{\mathrm{h}}\right)$ (Ibrahim et al., 2003). However, in our preliminary experiments, the $I_{\mathrm{h}}$ blocker ZD7288 did not abrogate the effects of leptin. Therefore

\footnotetext{
Received Sept. 25, 2009; revised Nov. 2, 2009; accepted Dec. 11, 2009.

This work was supported by United States Public Health Service Grants NS 38809, NS 43330, and DK 68098. We thank Elizabeth A. Rick and Dr. Taiping Jia for their expert technical contribution.

Correspondence should be addressed to either Dr. Martin J. Kelly or Dr. Oline K. Ronnekleiv, Department of Physiology and Pharmacology, L334, Oregon Health \& Science University, Portland, OR 97239-3098, E-mail: kellym@ohsu.edu or ronnekle@ohsu.edu.

DOI:10.1523/JNEUROSCI.4816-09.2010

Copyright $\odot 2010$ the authors $\quad 0270-6474 / 10 / 301560-06 \$ 15.00 / 0$
}

we focused on the potential role of TRPC channels in mediating leptin's effects.

The mammalian TRPC channel family consists of seven members, TRPC1-TRPC7, that appear to function as receptoroperated channels, analogous to the transient receptor potential (TRP) channels involved in Drosophila phototransduction (Clapham et al., 2005). With the exception of TRPC2, these channels are widely distributed in the mammalian brain (Venkatachalam and Montell, 2007). The TRP channels contain subunits with six membrane-spanning domains that coassemble as tetrameric complexes (Clapham et al., 2005), and they appear to coassemble as homomeric or heteromeric channels consisting of either the TRPC1, TRPC4, and TRPC5 subfamily or the TRPC3, TRPC6, and TRPC7 subfamily (Hofmann et al., 2002).

Therefore in the present study, we investigated the potential role of TRPC channels in mediating leptin's depolarizing effects. Indeed, we have identified a Janus 2 tyrosine kinase (Jak 2)dependent pathway that activated TRPC1, 4, and 5 channels via stimulation of PI3 kinase and PLC $\gamma 1$.

\section{Materials and Methods}

Animals and treatments. All animal treatments are in accordance with institutional guidelines based on National Institutes of Health standards, and were performed with Institutional Animal Care and Use Committee approval at the Oregon Health \& Science University. Female and male EGFP-POMC transgenic mice were selectively bred in-house, and maintained under controlled temperature $\left(25^{\circ} \mathrm{C}\right)$ and photoperiod $(12 / 12 \mathrm{~h}$ light/dark cycle) conditions with food and water ad libitum. Adult females were ovariectomized under ketamine/xylazine ( 1 and $0.1 \mathrm{mg} / 10 \mathrm{~g}$, respectively) anesthesia and allowed to recover for 1 week. 
A

B

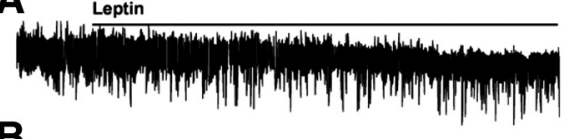

$\mathrm{Ca}^{2+}$ Free Leptin

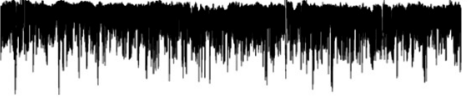

C
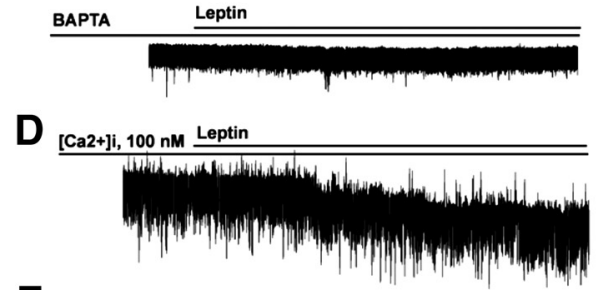

E

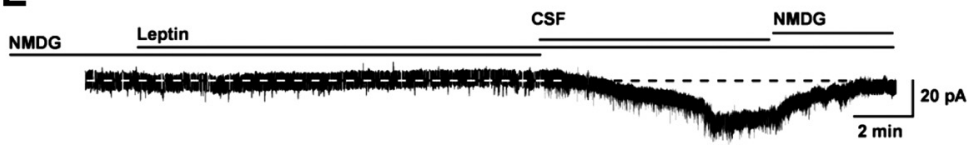

Figure 1. The leptin-induced inward current is mediated by an increase in cationic conductance. $\boldsymbol{A}-\boldsymbol{E}$, Representative traces of the leptin-induced currents in the presence of a $\mathrm{Ca}^{2+}$-free extracellular solution $(\boldsymbol{B})$ or an internal solution with $10 \mathrm{~mm}$ BAPTA instead of $11 \mathrm{~mm}$ EGTA $(\boldsymbol{C})$ or $100 \mathrm{~nm}\left[\mathrm{Ca}^{2+}\right]_{i}(\boldsymbol{D})$ or a NMDG solution $(\boldsymbol{E})$. $\boldsymbol{F}$, Bar graphs summarizing the effects of BAPTA, $\mathrm{Ca}^{2+}$, and NMDG on the leptin-induced inward currents. Both extracellular $\mathrm{Ca}^{2+}$-free and low- $\mathrm{Na}^{+}$external solutions attenuated the leptin-induced inward currents, indicative of a cation-selective (e.g., TRPC) channel. $V_{\text {hold }}=-60 \mathrm{mV}$. ${ }^{* * *} p<0.001$; ${ }^{* *} p<0.01$, significantly different from the control group (black bar). Cell numbers tested are indicated.
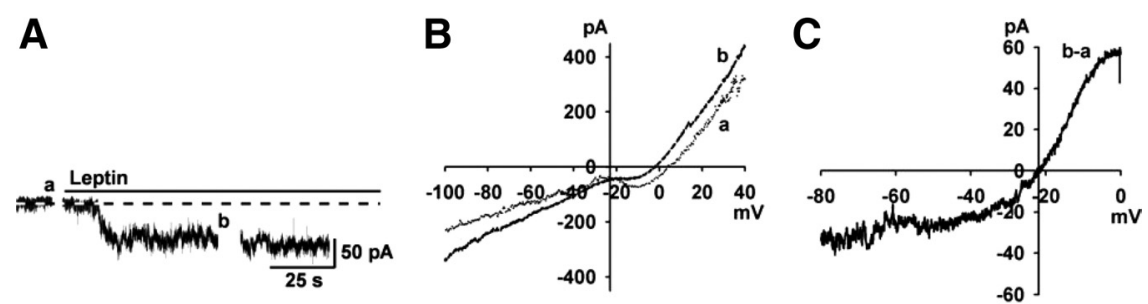

D

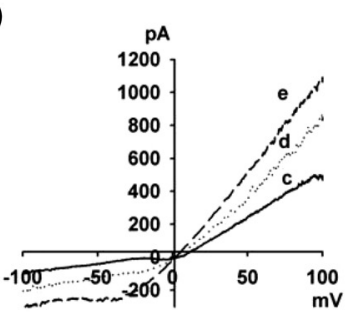

E
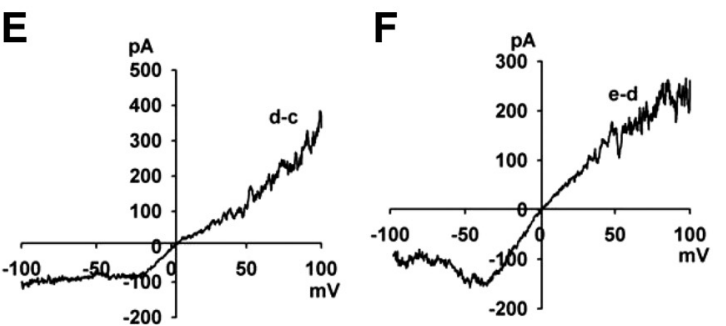

Figure 2. The leptin-activated inward current and its $/-V$ relationship in POMC neurons. $A$, Rapid application of $100 \mathrm{~nm}$ leptin induced a robust inward current with an internal solution containing $130 \mathrm{~mm} \mathrm{CsCl} V_{\text {hold }}=-60 \mathrm{mV}$. B, Voltage ramps from +100 to $-100 \mathrm{mV}$ were applied (over $2 \mathrm{~s}$ ) before (a) and during (b) the treatment with leptin in $A$. C, The $I-V$ relationship for the leptin-induced current was obtained by digital subtraction in $\boldsymbol{B}$. D-F, The $/-V$ relationships of NSCC after the exchange of $\mathrm{Cs}^{+}$for the external $\mathrm{Na}^{+}$and $\mathrm{K}^{+}$. The $I-V$ relationship was obtained using a voltage ramp from $+100 \mathrm{mV}$ to $-100 \mathrm{mV}$ for $500 \mathrm{~ms}$. $\boldsymbol{D}$, Voltage ramps were applied before (c) and after (d) the exchange of $\mathrm{Cs}^{+}$for the external $\mathrm{Na}^{+}$and $\mathrm{K}^{+}$, and during treatment with leptin (e). $\boldsymbol{E}$, The $I-V$ relationship was obtained by subtracting c from $\mathrm{d}$. An inward current was enhanced by $\mathrm{Cs}^{+}$. $\boldsymbol{F}$, The $I-V$ relationship was obtained by subtracting $d$ from e. Leptin induced an inward current, and the $I-V$ relationship showed a typical doubly rectifying shape.

Electrophysiological solutions/drugs. Normal aCSF $\left(35^{\circ} \mathrm{C}\right)$ and normal pipette solution were used in electrophysiological recording (Ibrahim et al., 2003) (supplemental Methods, available at www.jneurosci.org as supplemental material). When the cationic blocker $\mathrm{La}^{3+}$ was added to the bath, a HEPES-buffered CSF solution was used (Zhang et al., 2008). In some experiments, low- $\mathrm{Na}^{+}(5 \mathrm{mM})$ HEPES-buffered CSF solution and $\mathrm{Ca}^{2+}$ free extracellular CSF solution were used, where $\mathrm{N}$-methyl-D-gluc- amine $\left(\mathrm{NMDG}^{+}\right)$replaced $\mathrm{Na}^{+}$, and $\mathrm{Mg}^{2+}$ replaced $\mathrm{Ca}^{2+}$, respectively. For experiments measuring the ramp current-voltages $(I-V \mathrm{~s})$, $\mathrm{K}^{+}$-gluconate in the normal internal solution was replaced with $\mathrm{Cs}^{+}$-gluconate $(\mathrm{pH} 7.35$ with $\mathrm{CsOH}$ ), and the extracellular solution contained $\mathrm{Na}^{+}, \mathrm{K}^{+}, I_{\mathrm{h}}(\mathrm{HCN}), \mathrm{Ca}^{2+}$, and $\mathrm{GABA}_{\mathrm{A}}$ channel blockers (in mM: $\mathrm{NaCl}, 126$; 4-aminopyridine, $5 ; \mathrm{KCl}, 2.5 ; \mathrm{MgCl}_{2}, 1.2 ; \mathrm{CsCl}$, 2; $\mathrm{CaCl}_{2}, 1.4 ; \mathrm{CoCl}_{2}, 1$; nifedipine, 0.01 ; HEPES, 20; $\mathrm{NaOH}, 8$; glucose, 10; tetrodotoxin, 0.001 ; picrotoxin, 0.1 ). Ramp $I-V$ s were also recorded in a solution in which both $\mathrm{Na}^{+}$ and $\mathrm{K}^{+}$were replaced with same concentration of $\mathrm{Cs}^{+}$(pH 7.35 with $\left.\mathrm{CsOH}\right)$.

All drugs were purchased from Calbiochem unless otherwise specified. Leptin was provided by Dr. Parlow (Harbor-UCLA Medical Center, Torrance, CA) through the National Hormone and Peptide Program. The Jak2 inhibitor (E)-N-benzyl-2-cyano-3-(3,4-dihydroxyphenyl)acrylamide (AG 490), the PLC inhibitor U73122, the less active analog U73343 and the PI3 kinase inhibitor wortmannin (Alomone Laboratories) were dissolved in dimethylsulfoxide (DMSO) as stock solutions. The selective PLC $\gamma$ inhibitor 1-O-octadecyl-2- O-methylrac-glycero-3-phosphorylcholine (ET-18-OCH3) was dissolved in $\mathrm{H}_{2} \mathrm{O}$. 1,2-Bis-(o-aminophenoxyethane)- $N, N, N^{\prime}, N^{\prime}$-tetra-acetic acid (BAPTA) tetrasodium salt was dissolved in the internal solution at a $10 \mathrm{~mm}$ concentration. The ion channel blockers/ activators used were as follows: 1-[ $\beta$-[3-(4-methoxyphenyl)propoxy]-4methoxyphenethyl]-1 $H$-imidazole hydrochloride (SKF96365), 2-aminoethyl diphenylborinate (2-APB), flufenamic acid (FFA), and 2-acetyl1-oleoyl-sn-glycerol (OAG) all were dissolved in DMSO. $\mathrm{LaCl}_{3}$ was dissolved in $\mathrm{H}_{2} \mathrm{O}$.

Visualized whole-cell patch recording. Slices were prepared as described previously (Ibrahim et al., 2003) (supplemental Methods, available at www.jneurosci.org as supplemental material). Standard whole-cell patch recording procedures and pharmacological testing were as previously described (Zhang et al., 2008). To display reversal potential and rectification characteristics of the ligand-activated currents, $I-V$ plots constructed by voltage ramps from +100 to $-100 \mathrm{mV}$ were applied at $500 \mathrm{~ms}$ or 2 sintervals from a holding potential of $-60 \mathrm{mV}$.

Cell harvesting of dispersed mouse POMC neurons and single-cell RT-PCR. These procedures were as described previously (Ibrahim et al., 2003; Zhang et al., 2008). The primers were as follows: POMC (200 bp product, accession number NM_008895, forward primer 145-164 nt, reverse primer 326-344 nt); PLC $\gamma 1$ (111 bp product, accession number NM_021280, forward primer $539-558 \mathrm{nt}$, reverse primer $630-$ 649 nt); PLC $\gamma 2$ (237 bp product, accession number NM_172285, forward primer 29052925 nt, reverse primer 3121-3141 nt). Primers for all TRPC channel subunits were as published previously (Zhang et al., 2008). Each reaction was amplified for 50 cycles using a Bio-Rad C1000 Thermal Cycler (Bio-Rad). All scRT-PCR products were confirmed by sequencing.

Data analysis. Comparisons between different drug treatments were performed using a one-way ANOVA analysis with the Newman-Keuls 
post hoc test. Differences were considered statistically significant if $p<0.05$. All data are presented as mean \pm SEM.

\section{Results}

Leptin activates a $\mathrm{Ca}^{2+}$-dependent nonselective cationic channel

To characterize the ionic mechanism(s) underlying the leptin-induced depolarization, we analyzed the reversal potentials of the leptin-induced currents at a holding potential of $-60 \mathrm{mV}$. A saturating concentration of leptin (100 nM) (Cowley et al., 2001; our preliminary findings) increased the frequency of action potential and induced a depolarization (supplemental Fig. 1, available at www. jneurosci.org as supplemental material) or an inward current with a peak amplitude of $9.1 \pm 0.6 \mathrm{pA}$ in $96 \%$ of POMC neurons $(n=25$, resting membrane potential $=-57.3 \pm 0.8 \mathrm{mV}$ ) (Fig. $1 A, F)$. Replacement of extracellular $\mathrm{Ca}^{2+}$ with $\mathrm{Mg}^{2+}$ attenuated the leptin-induced current (Fig. $1 B$ ), reducing the inward current to $1.06 \pm 0.49 \mathrm{pA}(n=5, p<0.001$ vs control) (Fig. $1 F$ ). An internal solution in which $11 \mathrm{~mm}$ EGTA was replaced with 10 mM BAPTA significantly reduced the leptin-induced current $(2.4 \pm 0.8 \mathrm{pA} ; n=$ $6 ; p<0.01$ vs control) (Fig. $1 C, F)$. After 15 min dialysis with an internal solution containing $0.6 \mathrm{mM} \mathrm{Ca}^{2+}$ and $1 \mathrm{~mm}$ EGTA (the intracellular $\mathrm{Ca}^{2+}$ concentration was estimated to be $\sim 100 \mathrm{nM}$ ), the leptinactivated current was increased by $179.8 \%$ $(25.5 \pm 5.1 \mathrm{pA} ; n=4 ; p<0.001$ vs control) (Fig. $1 D, F)$, suggesting that the leptin response was potentiated by the elevation of intracellular $\mathrm{Ca}^{2+}$. Under physiological conditions, the inward current of a NSCC is mainly mediated by extracellular $\mathrm{Na}^{+}$. When the extracellular $\mathrm{Na}^{+}$concentration was reduced to $5 \mathrm{~mm}$ by replacing extracellular $\mathrm{Na}^{+}$ with $\mathrm{NMDG}^{+}$, a large organic cation that does not pass through cationic channels, the leptin-induced inward currents were greatly inhibited (Fig. $1 E)$. The inward current decreased from $9.1 \pm 0.6 \mathrm{pA}$ in the control CSF bath to $0.1 \pm 0.1 \mathrm{pA}(n=4, p<0.001$ vs control) (Fig. $1 F$ ). Therefore, a $\mathrm{Na}^{+}$-dependent NSCC current appears to be the dominant inward current activated by leptin.

To examine the $I-V$ relationship of the leptin-activated NSCC currents over a wider range of membrane potentials, experiments were conducted using a $\mathrm{Cs}^{+}$-gluconate-based internal solution to block voltage-gated $\mathrm{K}^{+}$channels. Also, 4-AP (5 mM) and Cs ${ }^{+}(1$ $\mathrm{mM}$ ) were included in a HEPES-buffered CSF to block the A-type $\mathrm{K}^{+}$and h-currents, respectively. As shown in Figure $2 A-C$, the leptin-activated NSCC currents reversed near $-20 \mathrm{mV}(-21.2 \pm$ $1.0 \mathrm{mV}, n=5$ ).

In heterologous TRPC5 expression systems, $\mathrm{Cs}^{+}$is a more effective charge carrier $\left(\mathrm{Cs}^{+}>\mathrm{K}^{+}>\mathrm{Na}^{+}\right.$) (Lee et al., 2003); therefore, we replaced $\mathrm{Na}^{+}$and $\mathrm{K}^{+}$with $\mathrm{Cs}^{+}$in the extracellular analyzed from each animal.
E

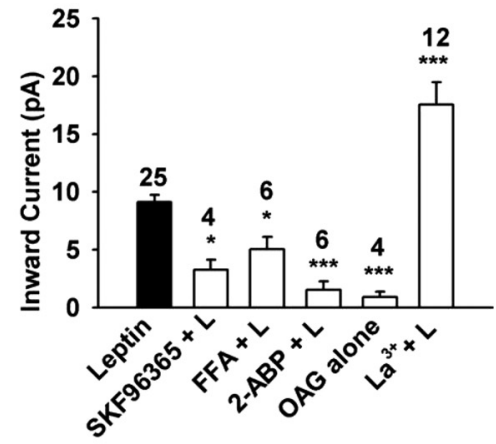

$20 \mathrm{pA}$

G

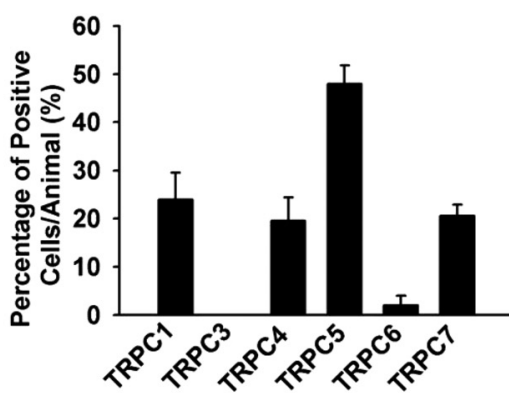

Figure 3. TRPC channels are expressed in POMC neurons and activated by leptin. $\boldsymbol{A}-\boldsymbol{D}$, Representative traces of the leptin, FFA $(100 \mu \mathrm{M}), 2-A B P$, and $\mathrm{La}^{3+}$ on the leptin-induced inward currents and the effect of OAG on the baseline current. La ${ }^{3+}$

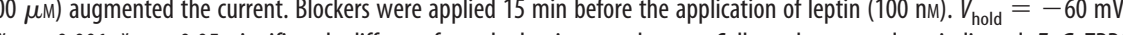
channel transcripts were measured in POMC neurons by sCRT-PCR. $F$, Representative gel images illustrating the mRNA expression of TRPC channel subunits in hypothalamic EGFP-POMC neurons harvested from intact male mice. Ninety-five percent of the harvested EGFP-POMC neurons contained transcripts for POMC. The expected size of PCR products for each TRPC channel subunit is dicated. $L$ is the 100 bp DNA ladder. Negative $(-R T)$ control cell was amplified from a harvested POMC neuron without RT. control was amplified using CDNA from mouse basal hypothalamic tissue. G, Bar graph represents the mean \pm EM of the percentage of POMC neurons expressing each TRPC subunit mRNA in 70 cells from five mice. An average of 14 cells were

solution. As shown in Figure $2 \mathrm{D}-\mathrm{F}, \mathrm{Cs}^{+}{ }^{+}$increased the baseline conductance (Fig. 2E), suggesting that TRPC channels are constitutively active in POMC neurons. Moreover, the $I-V$ relationship of the leptin-activated currents exhibited a negative slope conductance at voltages around $-50 \mathrm{mV}$ (Fig. $2 \mathrm{~F}$ ), similar to $I / V$ relationships for TRPC5 in HEK cells (Strübing et al., 2001).

\section{Pharmacological analysis of TRPC channels in POMC neurons}

To examine whether the leptin-activated currents were sensitive to TRPC channel blockers, an ensemble of TRPC channel blockers were applied to POMC neurons (Fig. 3A-E).2-APB is a potent blocker of TRPC3, 4, 5, and 6 (Clapham et al., 2005). Indeed, extracellular 2-APB $(100 \mu \mathrm{M})$ robustly blocked the leptininduced currents by $83.4 \%$ ( $1.5 \pm 0.7 \mathrm{pA}, n=6$ vs control, $p<$ 0.001 ) (Fig. $3 A, E$ ). However, 2-APB is also a blocker of inositol1,4,5-trisphosphate $\left(\mathrm{IP}_{3}\right)$ receptors. To determine whether the 


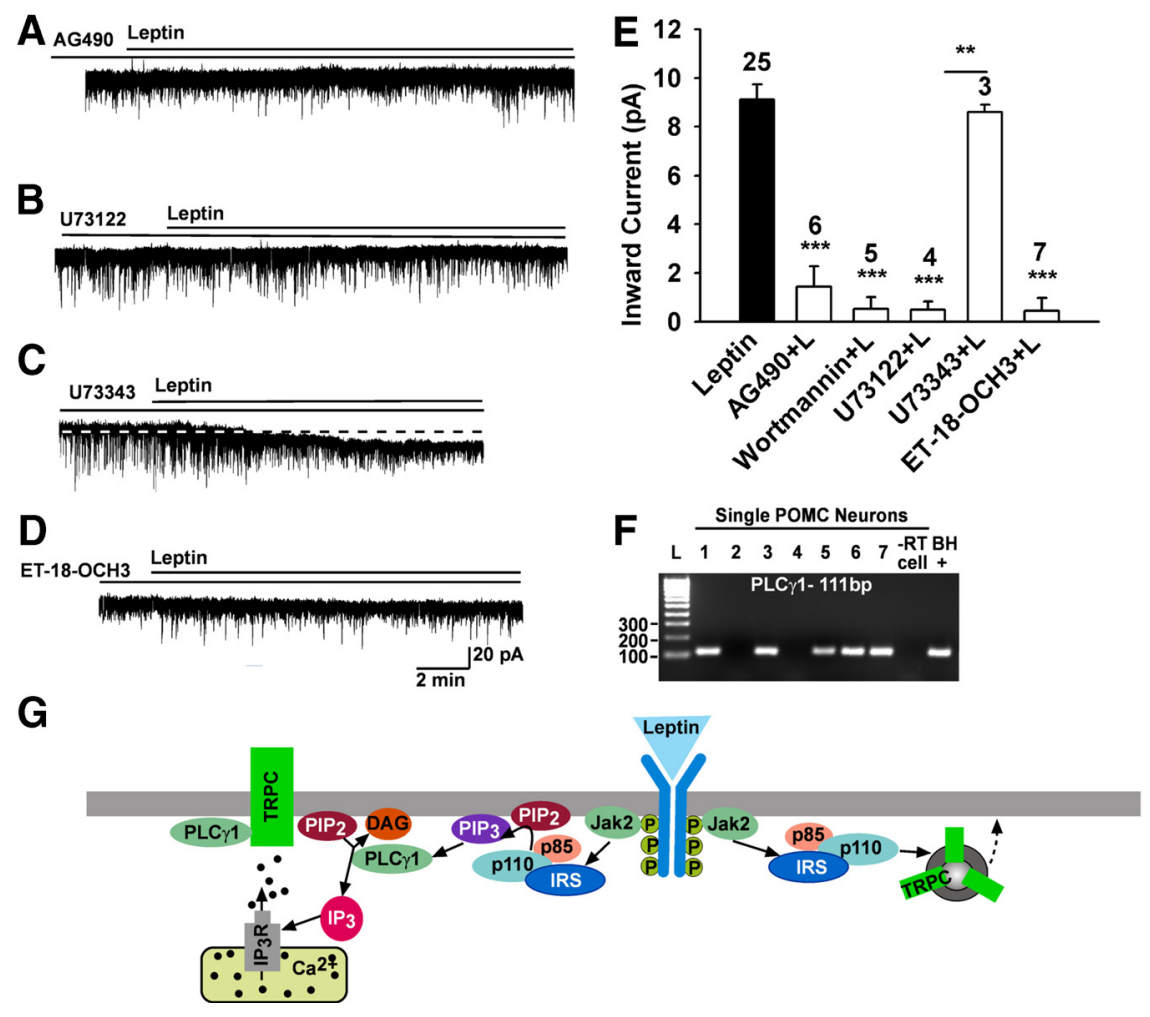

Figure 4. The leptin response requires Jak2, PI3 kinase, and PLC $\gamma$ activation. $A-D$, Representative traces of the leptin-induced currents in the presence or absence of kinase inhibitors. $\boldsymbol{E}$, Summary of the effects of the Jak2 inhibitor AG490 (10 $\mu \mathrm{M})$, PI3 kinase inhibitor wortmannin (100 nM), PLC inhibitor U73122 $(20 \mu \mathrm{m})$, and its inactive analog U73343 $(20 \mu \mathrm{M})$, and the PLC $\gamma$ inhibitor ET-18-0CH3 $(15 \mu \mathrm{m})$ on the leptin-induced inward current. Blockers were applied for $15 \mathrm{~min}$ before the application of leptin (100 nM). $V_{\text {hold }}=-60 \mathrm{mV} .{ }^{* *} p<0.01$, U73122 versus U73343 group; ${ }^{* * *} p<0.001$, significantly different from the leptin control group. Cell numbers tested are indicated. $\boldsymbol{F}$, Representative gel illustrating PLC $\gamma 1 \mathrm{mRNA}$ expression in POMC neurons. $-\mathrm{RT}$ cell and $\mathrm{BH}+$, processed without and with RT. G, A cellular model of leptin's signaling and TRPC channel activation in the POMC neurons. Based on our findings and other published data, we propose that leptin binds to its receptor (LRb) to activate Jak2, which phosphorylates IRS proteins and in turn activates PI3 kinase. PI 3 kinase subsequently activates PLC $\gamma 1$ to augment TRPC channel activity. PI3 kinase also stimulates rapid incorporation of functional TRPC channels into the plasma membrane. All of these signaling events enhance POMC neuronal excitability.

inhibitory effect of 2-APB was due to a direct blockade of TRPC channels or $\mathrm{IP}_{3}$ receptors, 2-APB $(100 \mu \mathrm{M})$ was dialyzed into the cells via the patch pipette. Intracellular 2-APB did not significantly affect the amplitude of the leptin-induced inward current $(9.2 \pm 1.3 \mathrm{pA}, n=4)$ (Fig. $3 B$ ), which indicates that 2-APB acts directly on TRPC channels to block the leptin response.

In addition, SKF96365 blocks TRPC3, TRPC5, TRPC6, and TRPC7 channels (Clapham et al., 2005). When cells were pretreated with $100 \mu \mathrm{M}$ SKF, the leptin-induced inward current was inhibited by $66.8 \%$ ( $3.0 \pm 0.9 \mathrm{pA}, n=4, p<0.05$ vs control) (Fig. $3 E)$. FFA $(100 \mu \mathrm{M})$, which is another potent blocker of TRPC3, 5, and 7 (Clapham et al., 2005) attenuated the leptin-induced inward current by $44.8 \%(5.0 \pm 2.0 \mathrm{pA}, n=6, p<0.05$ vs control $)$ (Fig. 3E).

In heterologous expression systems, micromolar concentrations of $\mathrm{La}^{3+}$ potentiate TRPC4 and TRPC5 activity (Schaefer et al., 2000; Strübing et al., 2001), but inhibit TRPC1, 3, 6, and 7 channels (Clapham et al., 2005). Indeed, we found that 100 $\mu \mathrm{M} \mathrm{La}^{3+}$ greatly potentiated the leptin-induced current by $92.4 \%$ $(17.5 \pm 1.9 \mathrm{pA}, n=12, p<0.001$ vs control) (Fig. $3 D, E)$.

PLC hydrolyzes $\mathrm{PIP}_{2}$ to yield diacylglycerol (DAG) and $\mathrm{IP}_{3}$, which in turn induces $\mathrm{Ca}^{2+}$ release from the endoplasmic reticulum. Since $\mathrm{IP}_{3}$ receptor antagonism with 2-ABP, did not atten- uate the actions of leptin, we examined the effects of DAG. TRPC3, 6, and 7 can be directly activated by OAG, a permeable analog of DAG (Hofmann et al., 1999), but when combined with TRPC1 and TRPC4 or 5, they are at best weakly activated (Strübing et al., 2003). We found that the OAG $(100 \mu \mathrm{M})$ had no effect on TRPC channel activity $(0.9 \pm 0.4 \mathrm{pA}, n=$ $4, p<0.001$ vs control) (Fig. 3C,E), indicating that DAG is not the final messenger for leptin signaling in POMC neurons. It also indicates that homomers or heteromers within the TRPC1, 4, and 5 subfamily are probably formed and activated in POMC neurons. Collectively, the pharmacological data would indicate that mainly TRPC4 and 5 channels are involved in the leptin-mediated depolarization of POMC neurons.

\section{TRPC channel transcripts are expressed in POMC neurons}

Based on the pharmacological profile of the leptin-evoked inward currents, we predicted that TRPC1, 4, and 5 would be expressed in POMC neurons. Thus, we performed scRT-PCR experiments to examine the expression of TRPC mRNA transcripts in POMC neurons. Five of the six TRPC channel subunits found in the brain (TRPC1 and TRPC4-7) were expressed in POMC neurons, whereas the TRPC3 subunit was not detected (Fig. $3 G)$. TRPC5 was the most prevalent subunit and was expressed in $48 \pm 4 \%$ of POMC neurons (Fig. $3 F, G$ ). Moreover, TRPC1, 4, and 7 were detected in $24 \pm$ $6 \%, 20 \pm 5 \%$, and $21 \pm 2 \%$ of the neurons, respectively (Fig. $3 G$ ). An insignificant number of POMC neurons expressed TRPC6. All negative controls, including cells $(n=5)$ and tissue RNA processed without RT (reverse transcriptase), were negative following RT-PCR. Therefore, TRPC1, 4, and 5 appear to be the predominant subfamily expressed in POMC neurons.

\section{Leptin receptor-mediated signaling pathway}

We next explored if the leptin receptor couples to the Jak2-PI3 kinase signaling pathway to affect TRPC channels. Indeed, the Jak inhibitor AG490 $(10 \mu \mathrm{M})$ potently blocked the effects of leptin $(1.4 \pm 0.8 \mathrm{pA}, n=6, p<0.001 \mathrm{vs}$ control) (Fig. $4 A, E)$. PI3 kinase is essential for leptin-induced activation (Hill et al., 2008) but it is also critical for the membrane insertion of TRPC channels (Bezzerides et al., 2004). Therefore, we examined the role of PI3 kinase in the leptin-induced inward current. The selective PI3 kinase inhibitor wortmannin (100 nM) blocked the leptininduced inward current by $94.2 \%(0.5 \pm 0.5 \mathrm{pA}, n=5, p<0.001$ vs control) (Fig. $4 E$ ). When cells were pretreated with the PLC inhibitor U73122 $(10 \mu \mathrm{M})$, the leptin-induced current was inhibited by $94.5 \%(0.5 \pm 0.3 \mathrm{pA}, n=4, p<0.001$ vs control) (Fig. $4 B, E)$, but the inactive analog U73343 $(10 \mu \mathrm{M})$ had no effect (8.6 $\pm 0.3 \mathrm{pA}, n=3, p<0.01$ vs U73122 group) (Fig. $4 C, E)$. This indicates that the LRb couples to Jak2 to activate PLC. Since 
leptin activates PLC $\gamma 2$ in human platelets (Dellas et al., 2007), we perfused the selective PLC $\gamma$ inhibitor ET-18-OCH3 (15 $\mu \mathrm{M})$ and found that it potently blocked the effects of leptin $(0.5 \pm 0.5 \mathrm{pA}$, $n=7, p<0.001$ vs control) (Fig. $4 D, E$ ). Finally, to determine whether the LRb is coupled through PLC $\gamma 1$ or PLC $\gamma 2$, we used scRT-PCR to identify the expression of these transcripts in POMC neurons (Fig. 4F). We found that the PLC $\gamma 1$ was expressed in $\sim 70 \%$ of POMC neurons. In contrast, PLC $\gamma 2$ mRNA was only detected in 1 of 30 neurons. Based on these results, it appears that leptin's coupling to TRPC channels in POMC neurons is through LRb-Jak2-PI3 kinase and PLC $\gamma 1$ signaling pathways (Fig. 4G).

\section{Discussion}

We have shown for the first time that leptin potently depolarizes hypothalamic POMC neurons by activating a TRPC conductance. We have concluded this based on several lines of evidence. First, the $I-V$ relationship for the leptin-induced current exhibited a negative slope conductance, outward rectification, and a reversal at $\sim 0 \mathrm{mV}$ (in $\mathrm{Cs}^{+}$). Second, the leptin current was significantly attenuated by the TRPC channel blockers 2-APB, FFA, and SKF96365. Moreover, the inward current was potentiated over twofold by $\mathrm{Ca}^{2+}$ and $\mathrm{La}^{3+}$, a characteristic of TRPC4 and 5 channels. Third, the leptin-induced inward current was for the most part abolished in low extracellular $\mathrm{Na}^{+}$. Finally, we found that individual POMC neurons express TRPC channel transcripts with TRPC5 being the most prevalent. Therefore, the cumulative evidence supports the conclusion that leptin excites POMC neurons predominantly through the activation of TRPC channels.

An initial indication that the leptin-induced current is mediated by TRPC channels was the characteristic $I-V$ relationship in the presence of a $\mathrm{K}^{+}$channel blocker (i.e., $\mathrm{Cs}^{+}$). The $I-V$ relationship resembled the $I-V$ relationship of heteromeric complexes of TRPC1 +4 or TRPC1 +5 subunits expressed in HEK cells with a negative slope conductance and pronounced outward rectification (Strübing et al., 2001; Clapham, 2003). Similar $I-V$ relationships have been obtained with the kisspeptin-activated currents in gonadotropin-releasing hormone (GnRH) neurons as well as mGluR1- and CCK2-induced currents in basolateral amygdala neurons, which all express a similar complement of TRPC channels as POMC neurons (Meis et al., 2007; Zhang et al., 2008).

The mammalian TRPC channels can be activated by G-proteincoupled receptors and receptor tyrosine kinases (Clapham et al., 2005). In fact, TRPC channels are probably one of the major targets for mGluR1 signaling in the CNS (Tozzi et al., 2003). Interestingly, TRPC1 and 5 are highly expressed in substantia nigra dopamine neurons, and the mGluR1 agonist dihydroxyphenylglycine-induced current exhibits an "S" shape $I-V$ plot (Tozzi et al., 2003), similar to what we see in POMC neurons. In addition, the peptides cholecystokinin via the CCK2 receptor and kisspeptin via the GPR54 receptor also activate TRPC1, 4, and 5 channels in amygdala (Meis et al., 2007) and preoptic GnRH (Zhang et al., 2008) neurons, respectively. The mGluR1, CCK2, and GPR54 receptors are $\mathrm{G}_{\mathrm{q}}$-coupled to PLC activation, and we did find that the PLC inhibitor U73122 inhibited the effects of leptin in POMC neurons. However, OAG had no effect, which fits with our findings that the DAG-sensitive TRPC3, 6, and 7 channels (Clapham et al., 2005) are not highly expressed in POMC neurons. Importantly, $\mathrm{La}^{3+}(100 \mu \mathrm{M})$ and $\mathrm{Ca}^{2+}$ greatly potentiated the leptin-induced current, which is a hallmark of TRPC4 and 5 activation (Clapham et al., 2005; Blair et al., 2009).
In addition, 2-APB and FFA attenuated the effects of leptin in POMC neurons. These blockers have a similar efficacy for the mGluR1 (Tozzi et al., 2003), CCK2 (Meis et al., 2007), and GPR54 (Zhang et al., 2008) activation of TRPC channels in neurons. Therefore, TRPC5 and to a lesser extent TRPC4 appear to be the key players in mediating the effects of leptin in POMC neurons based on the $I-V$ relationship, the pharmacological profile, and the subunit composition.

From a physiological perspective, the pleiotropic effects of leptin in POMC neurons are the most critical for both the shortterm and long-term modulation of POMC neuronal activity and the control of energy homeostasis. As has been demonstrated earlier (Hill et al., 2008), we found that the leptin-mediated excitation (inward current) is abrogated by inhibition of PI3 kinase activity, suggesting that the leptin-induced increase in POMC excitability is mediated via PI3 kinase. LRb is a member of the class I cytokine receptor family and signals through activation of Jak2 that mediates leptin signaling via several pathways, including the STAT3, MAPK, AMPK, and mTOR pathways. These pathways act coordinately to form a circuit that fully mediates the leptin response (Morris and Rui, 2009). We found the Jak2 inhibitor AG490 completely blocked the effects of leptin to activate TRPC channels. In addition, leptin via LRb signals through the insulin receptor substrate (IRS)-PI3 kinase pathway (Morton et al., 2005) to increase the activity of PI3 kinase and its association with IRS-2 in the hypothalamus (Niswender et al., 2001; Zhao et al., 2002).

In primary hippocampal neuronal cultures, activation of PI3 kinase increases the rapid membrane insertion of TRPC5 channels from an intracellular vesicular pool (Bezzerides et al., 2004). In addition, activation of PI3 kinase generates phosphatidylinositol-3,4,5-triphosphate $\left(\mathrm{PIP}_{3}\right)$, which appears to contribute to the translocation and activation of PLC $\gamma$ at the plasma membrane (Bae et al., 1998; Falasca et al., 1998; Rameh et al., 1998). Through its phospholipase catalytic domains, PLC $\gamma$ hydrolyzes $\mathrm{PIP}_{2}$ to generate two second messengers, DAG and IP3. Also, PLC $\gamma$ has enzyme-independent signaling properties acting through its other protein-protein interacting domains (Patterson et al., 2005). In fact, PLC $\gamma 1$ has a critical role in leptin signaling in POMC neurons, because the selective PLC $\gamma$ inhibitor Et-18-OCH3 completely blocked leptin's effects. However, all of the steps leading to channel opening following PLC activation are not fully understood (Schaefer et al., 2000), and the importance of PLC $\gamma$ activation in the overall leptin signaling needs to be determined.

Based on the current findings, we conclude that leptin binds to LRb to activate Jak2, which phosphorylates IRS proteins and in turn activates PI3 kinase; PI3 kinase subsequently activates PLC $\gamma 1$ to augment TRPC currents and POMC neuronal excitability (Fig. 4G). Since it is evident that leptin is essential for normal regulation of energy homeostasis, these signaling pathways are potential targets for the critical uncoupling events leading to leptin resistance in obesity and type II diabetes.

\section{References}

Bae YS, Cantley LG, Chen C-S, Kim S-R, Kwon K-S, Rhee SG (1998) Activation of phospholipase $\mathrm{C}-\gamma$ by phosphatidylinositol 3,4,5-trisphosphate. J Biol Chem 273:4465-4469.

Bezzerides VJ, Ramsey IS, Kotecha S, Greka A, Clapham DE (2004) Rapid vesicular translocation and insertion of TRP channels. Nat Cell Biol 6:709-720.

Blair NT, Kaczmarek JS, Clapham DE (2009) Intracellular calcium strongly potentiates agonist-activated TRPC5 channels. J Gen Physiol 133: 525-546.

Clapham DE (2003) TRP channels as cellular sensors. Nature 426:517-524. 
Clapham DE, Julius D, Montell C, Schultz G (2005) International union of pharmacology. XLIX. Nomenclature and structure-function relationships of transient receptor potential channels. Pharmacol Rev 57: 427-450.

Cowley MA, Smart JL, Rubinstein M, Cerdán MG, Diano S, Horvath TL, Cone RD, Low MJ (2001) Leptin activates anorexigenic POMC neurons through a neural network in arcuate nucleus. Nature 411:480-484.

Dellas C, Schäfer K, Rohm IK, Lankeit M, Leifheit M, Loskutoff DJ, Hasenfuss G, Konstantinides SV (2007) Leptin signalling and leptin-mediated activation of human platelets: importance of JAK2 and the phospholipases C $\gamma 2$ and $A_{2}$. Thromb Haemost 98:1063-1071.

Elmquist JK, Bjørbaek C, Ahima RS, Flier JS, Saper CB (1998) Distributions of leptin receptor mRNA isoforms in the rat brain. J Comp Neurol 395:535-547.

Falasca M, Logan SK, Lehto VP, Baccante G, Lemmon MA, Schlessinger J (1998) Activation of phospholipase $\mathrm{C} \gamma$ by PI 3-kinase-induced $\mathrm{PH}$ domain-mediated membrane targeting. EMBO J 17:414-422.

Hill JW, Williams KW, Ye C, Luo J, Balthasar N, Coppari R, Cowley MA, Cantley LC, Lowell BB, Elmquist JK (2008) Acute effects of leptin require PI3K signaling in hypothalamic proopiomelanocortin neurons in mice. J Clin Invest 118:1796-1805.

Hofmann T, Obukhov AG, Schaefer M, Harteneck C, Gudermann T, Schultz G (1999) Direct activation of human TRPC6 and TRPC3 channels by diacylglycerol. Nature 397:259-263.

Hofmann T, Schaefer M, Schultz G, Gudermann T (2002) Subunit composition of mammalian transient receptor potential channels in living cells. Proc Natl Acad Sci U S A 99:7461-7466.

Ibrahim N, Bosch MA, Smart JL, Qiu J, Rubinstein M, Rønnekleiv OK, Low MJ, Kelly MJ (2003) Hypothalamic proopiomelanocortin neurons are glucose-responsive and express K-ATP channels. Endocrinology 144:1331-1340.

Lee YM, Kim BJ, Kim HJ, Yang DK, Zhu MH, Lee KP, So I, Kim KW (2003) TRPC5 as a candidate for the nonselective cation channel activated by muscarinic stimulation in murine stomach. Am J Physiol Gastrointest Liver Physiol 284:G604-G616.

Meis S, Munsch T, Sosulina L, Pape H-C (2007) Postsynaptic mechanisms underlying responsiveness of amygdaloid neurons to cholecystokinin are mediated by a transient receptor potential-like current. Mol Cell Neurosci $35: 356-367$.
Morris DL, Rui L (2009) Recent advances in understanding leptin signaling and leptin resistance. Am J Physiol Endocrinol Metab 297:E1247-E1259.

Morton GJ, Gelling RW, Niswender KD, Morrison CD, Rhodes CJ, Schwartz MW (2005) Leptin regulates insulin sensitivity via phosphatidylinositol$3-\mathrm{OH}$ kinase signaling in mediobasal hypothalamic neurons. Cell Metab 2:411-420.

Niswender KD, Morton GJ, Stearns WH, Rhodes CJ, Myers MG Jr, Schwartz MW (2001) Intracellular signalling: key enzyme in leptin-induced anorexia. Nature 413:794-795.

Patterson RL, van Rossum DB, Nikolaidis N, Gill DL, Snyder SH (2005) Phospholipase C- $\gamma$ : diverse roles in receptor-mediated calcium signaling. Trends Biochem Sci 30:688-697.

Powis JE, Bains JS, Ferguson AV (1998) Leptin depolarizes rat hypothalamic paraventricular nucleus neurons. Am J Physiol 274:R1468-R1472.

Rameh LE, Rhee SG, Spokes K, Kazlauskas A, Cantley LC, Cantley LG (1998) Phosphoinositide 3-kinase regulates phospholipase $\mathrm{C} \gamma$-mediated calcium signaling. J Biol Chem 273:23750-23757.

Schaefer M, Plant TD, Obukhov AG, Hofmann T, Gudermann T, Schultz G (2000) Receptor-meidated regulation of the nonselective cation channels TRPC4 and TRPC5. J Biol Chem 275:17517-17526.

Strübing C, Krapivinsky G, Krapivinsky L, Clapham DE (2001) TRPC1 and TRPC5 form a novel cation channel in mammalian brain. Neuron 29: 645-655.

Strübing C, Krapivinsky G, Krapivinsky L, Clapham DE (2003) Formation of novel TRPC channels by complex subunit interactions in embryonic brain. J Biol Chem 278:39014-39019.

Tozzi A, Bengtson CP, Longone P, Carignani C, Fusco FR, Bernardi G, Mercuri NB (2003) Involvement of transient receptor potential-like channels in responses to mGLuR-I activation in midbrain dopamine neurons. Eur J Neurosci 18:2133-2145.

Venkatachalam K, Montell C (2007) TRP channels. Annu Rev Biochem 76:387-417.

Zhang C, Roepke TA, Kelly MJ, Rønnekleiv OK (2008) Kisspeptin depolarizes GnRH neurons through activation of TRPC-like cationic channels. J Neurosci 28:4423-4434.

Zhao AZ, Huan JN, Gupta S, Pal R, Sahu A (2002) A phosphatidylinositol 3kinase-phosphodiesterase 3B-cyclic AMP pathway in hypothalamic action of leptin on feeding. Nat Neurosci 5:727-728. 